DR RANGI KANDANE-RATHNAYAKE (Orcid ID : 0000-0001-5397-1482)

DR LEONID DE GUZMAN ZAMORA (Orcid ID : 0000-0002-4209-4442)

DR LANIYATI HAMIJOYO (Orcid ID : 0000-0002-1310-674X)

PROFESSOR MASAYOSHI HARIGAI (Orcid ID : 0000-0002-6418-2603)

PROFESSOR SANG-CHEOL BAE (Orcid ID : 0000-0003-4658-1093)

DR ERIC MORAND (Orcid ID : 0000-0002-9507-3338)

Article type : Original Article

\title{
Development of the Asia Pacific Lupus Collaboration cohort
}

\section{Running title: APLC cohort}

Rangi Kandane-Rathnayake ${ }^{1 *}$, Vera Golder ${ }^{1}$, Worawit Louthrenoo ${ }^{2}$, Shue-Fen Luo ${ }^{3}$, Yeong-Jian Jan $\mathrm{Wu}^{3}$, Zhanguo $\mathrm{Li}^{4}$, Yuan $\mathrm{An}^{4}$, Aisha Lateef ${ }^{5}$, Sargunan Sockalingam ${ }^{6}$, Sandra V. Navarra ${ }^{7}$, Leonid Zamora $^{7}$, Laniyati Hamijoyo ${ }^{8}$, Yasuhiro Katsumata ${ }^{9}$, Masayoshi Harigai ${ }^{9}$, Madelynn Chan $^{10}$, Sean $\mathrm{O}^{\prime}$ Neill $^{11}$, Fiona Goldblatt ${ }^{12,13}$, Yanjie Hao ${ }^{14}$, Zhuoli Zhang ${ }^{14}$, Jamal Al-Saleh ${ }^{15}$, Munther Khamashta ${ }^{15}$, Tsutomu Takeuchi ${ }^{16}$, Yoshiya Tanaka ${ }^{17}$, Sang-Cheol Bae ${ }^{18}$, Chak Sing Lau ${ }^{19}$, Alberta Hoi ${ }^{1}$, Mandana Nikpour $^{20}$, Eric F. Morand ${ }^{1}$

${ }^{1}$ School of Clinical Sciences at Monash Health, Monash University, Clayton, VIC, Australia

${ }^{2}$ Chiang Mai University Hospital, Chiang Mai, Thailand

${ }^{3}$ Chang Gung Memorial Hospital, Taipei and Keelung, Taiwan

${ }^{4}$ People's Hospital, Peking University Health Science Center, Beijing, China

${ }^{5}$ National University Hospital, Singapore

${ }^{6}$ University of Malaya, Malaysia

${ }^{7}$ University of Santo Tomas Hospital, Philippines

${ }^{8}$ University of Padjadjaran, Indonesia

${ }^{9}$ Tokyo Women's Medical University, Japan

${ }^{10}$ Tan Tock Seng Hospital, Singapore

This is the author manuscript accepted for publication and has undergone full peer review but has not been through the copyediting, typesetting, pagination and proofreading process, which may lead to differences between this version and the Version of Record. Please cite this article as doi: $10.1111 / 1756-185 X .13431$

This article is protected by copyright. All rights reserved 
${ }^{11}$ Rheumatology Liverpool Hospital, SWS Clinical School, UNSW and the Ingham Institute for Applied Medical Research, NSW, Australia

${ }^{12}$ Royal Adelaide Hospital, Adelaide, Australia

${ }^{13}$ Flinders Medical Centre, Adelaide, Australia

${ }^{14}$ Peking University First Hospital, Beijing, China

${ }^{15}$ Dubai Hospital, Dubai, United Arab Emirates

${ }^{16}$ Keio University School of Medicine, Tokyo, Japan

${ }^{17}$ University of Occupational and Environmental Health, Kitakyushu, Japan

${ }^{18}$ Hanyang University Hospital for Rheumatic Diseases, Seoul, South Korea

${ }^{19}$ University of Hong Kong, Hong Kong

${ }^{20}$ St. Vincent's Hospital, Melbourne, Australia

Corresponding author: Dr Rangi Kandane-Rathnayake

Monash University, School of Clinical Sciences at Monash Health

Monash Medical Centre, 246 Clayton Road, Clayton VIC 3168, AUSTRALIA

Telephone: + 61385722561

E-mail: rangi.kandane-rathnayake@monash.edu

Keywords: lupus (or SLE), Asia-Pacific region, LLDAS, APLC

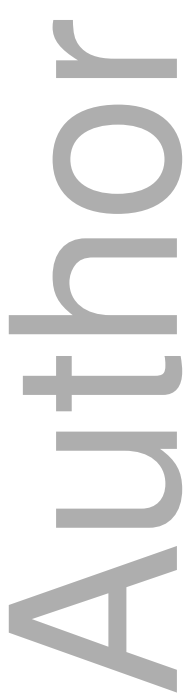

This article is protected by copyright. All rights reserved 


\section{Abstract}

AIM: The aim of this manuscript is to describe the development of the Asia Pacific Lupus Collaboration (APLC) cohort.

METHOD: The APLC cohort is an ongoing, prospective longitudinal cohort. Adult patients who meet either the American College of Rheumatology (ACR) Modified Classification Criteria for SLE, or the Systemic Lupus International Collaborating Clinics (SLICC) Classification Criteria, and provide informed consent are recruited into the cohort. Patients are routinely followed up at 3- to 6-monthly intervals. Information on demographics, clinical manifestations, treatment, pathology results, outcomes, and patient reported quality of life (SF36 version 2) are collected using a standardised case report form. Each site is responsible for obtaining local ethics and governance approval, patient recruitment, data collection, and data transfer into a centralised APLC database.

RESULTS: The latest APLC cohort comprises 2160 patients with $>12,000$ visits from Australia, China, Hong Kong, Indonesia, Japan, Malaysia, Philippines, Singapore, Taiwan and Thailand. The APLC has proposed the Lupus Low Disease Activity State (LLDAS) as a T2T endpoint, and reported several retrospective and cross sectional analyses consistent with the validity of LLDAS. Longitudinal validation of LLDAS as a T2T endpoint is currently underway.

CONCLUSION: The APLC cohort is one of the largest contemporary SLE patient cohorts in the world. It is the only cohort with substantial representation of Asian patients. This cohort represents a unique resource for future clinical research including evaluation of other endpoints and quality of care.

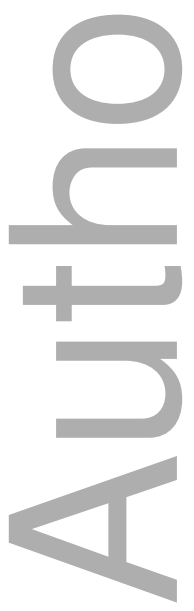

This article is protected by copyright. All rights reserved 


\section{INTRODUCTION}

Systemic lupus erythematosus (SLE or lupus) is a heterogeneous, autoimmune disease with a wide spectrum of clinical manifestations caused by autoimmune-mediated inflammation of multiple organs (1). The crude incidence of SLE in the Asia Pacific region ranges from $0.9-3.1$ per 100, 000 person-years, while the prevalence ranges from 4.3 to 45.3 per 100,000 (2). SLE patients, predominantly young women, suffer from severe morbidity and mortality, and hence have significantly impaired health related quality of life (HRQoL) (3). Tissue inflammation associated with SLE, and the unwanted effects of treatment, result in permanent organ damage in up to $61 \%$ of patients within 7 years of lupus diagnosis (4). Patients are generally treated with a combination of glucocorticoids, anti-malarial drugs and non-specific immunosuppressants, and there is no targeted therapeutic regimen effective for all patients (5). Despite combination therapy, significant proportion of patients suffer inadequate disease control, severe toxicity from medications, and inexorably accrue permanent organ damage over time (6). SLE is more prevalent and more severe in Asians $(7,8)$, and is phenotypically distinct from Caucasian SLE patients with a greater burden of renal disease and cardiovascular complications (9). In Asia, infections, high disease activity, renal disease and cardiovascular events are the leading causes of mortality among SLE patients (10).

For many years, there have been attempts to quantify heterogeneous states of active SLE to assist with patient assessment and trial design (11). However recently, the research momentum has turned towards defining treatment response endpoints or outcome measures $(12,13)$. This is partly driven from evidence in rheumatoid arthritis (RA), where treat to target (T2T) approaches such as achieving remission or low disease activity (LDA) state have proven to result in improved clinical outcomes (14). A small but significant proportion of RA patients achieve empirically validated definitions of remission, and this has provided powerful motivation to adopt remission as a treatment target in RA clinical practice, with the result that large proportions of patients achieve at least LDA. Unfortunately in SLE, remission is a very difficult target to achieve; existing remission definitions are so stringent only few attain remission (15), and the relapsing/flaring nature of SLE makes remission difficult to sustain (16).

Given the difficulty in attaining remission in SLE, at least with current treatments, targeting a low disease state may be a more achievable and sustainable outcome for T2T approaches. Prior studies in RA have shown that patients who achieved low disease activity (LDA) had favourable outcomes and improved well-being (17). The priority of empirically generating a LDA definition in lupus was recently reported by the SLE T2T International Task 
Force (13). This context provided inspiration to form the Asia Pacific Lupus Collaboration (APLC), and consequently to develop the APLC cohort, in order to conduct a longitudinal, prospective study to objectively define and validate a low disease activity state for lupus. Such a measure has the potential not only as a novel trial endpoint but also as the foundation for a T2T approach to routine patient management.

\section{METHODS}

Organisation and governance of the APLC

The APLC was formed in late 2012, bringing together physicians and researchers in the Asia Pacific region with the common goal of improving outcomes for SLE patients. The APLC has since grown to constitute 23 sites in 13 countries (Figure 1). Each site has signed a Memorandum of Understanding (MOU) that states the rules under which APLC operates. In addition, each institute has signed a legally binding collaborative research agreement (CRA) to conduct the LLDAS study. The APLC has formalised a steering committee to ensure transparency and accountability, oversee resource utilisation, provide research focus and optimise outputs. The APLC has established policies including a Publication Policy and Data Access Policy to manage a range of contingencies.

\section{Lupus Low Disease Activity State (LLDAS)}

The approach to define a low disease activity state for lupus began with the recognition that patients with low disease activity are more homogeneous than patients who have high disease activity, as the heterogeneity of lupus stems from the diverse range of features of active disease that diminishes as patients respond (12). This recognition permitted the development of a definition that avoids the complexity intrinsic to quantification of heterogeneous states of active disease.

The APLC consensus definition of the Lupus Low Disease Activity State (LLDAS) was defined using Delphi methods and nominal group technique, which support face and content validity, wherein 56 items generated by a panel of experts were reduced to five items forming a definition of LLDAS with high levels of agreement (18). The final list of five items defining LLDAS is depicted in Figure 2. The initial validation of LLDAS was performed retrospectively using data from a single centre, and attainment of LLDAS was found to be associated with improved patient outcomes, including lower disease activity during follow ups, fewer flares, lower prednisolone dose during follow-up, and less new organ damage (18). These findings 
provided preliminary evidence for the validity of the APLC definition of LLDAS, and its ability to predict favourable patient outcomes. Several other retrospective studies have since confirmed the association of LLDAS with protection from damage accrual, and it has been evaluated as an endpoint in two clinical trials (19-23). Using the APLC cohort, we are now in the process of executing a study to evaluate the validity of LLDAS prospectively, in a large, international, multi-centre patient population. The hypothesis being tested is that achieving LLDAS is associated with reduction in organ damage and improved quality of life. In addition, the APLC cohort data are, and will be used for many other scientific purposes in the years to come.

\section{$\underline{\text { Patient recruitment and consent }}$}

All patients must meet either the 1997 American College of Rheumatology (ACR) Modified Classification Criteria for SLE (24), with at least 4 of the 11 items; or fulfil the Systemic Lupus International Collaborating Clinics (SLICC) 2012 Classification Criteria (25), with at least 4 of the 17 items or with lupus nephritis in the presence of at least one immunological criteria. Principal Investigators at each site are responsible for identifying eligible patients, who can be either newly diagnosed or pre-existing SLE patients; age must be 18 years or over, and patients must be competent to provide informed consent. Individual centres obtain valid written informed consent in accordance with local authority regarding ethical conduct of human research. Human research ethics approvals have been obtained at each participating site. In addition, Monash University ethics approval has been obtained to store the pooled database, perform analyses and subsequently publish the findings. The first patient was recruited into the APLC cohort in November 2013 in Thailand, and recruitment is still ongoing.

\section{Data collection}

APLC investigators at participating sites collect data at patients' 3 to 6 -monthly routine visits using a standardised case report form (CRF). Table 1 summarises the data items collected at recruitment (baseline), at subsequent routine follow-ups and at annual visits. In brief, demographics and classification criteria (ACR (24)and SLICC (25)) are collected at baseline visit; variables related to organ damage accrual (SLICC-ACR Damage Index (SDI) (26)) and quality of life (SF36 version 2 (27)) are collected at baseline and annual visits, and data on disease activity (SLEDAI-2k (28)), flare index (29), Physician Global Assessment (PGA 0-3) (30), mortality, pathology and treatment (prednisolone, anti-malarial and immunosuppressant use) are captured at each visit( baseline/annual/routine visits). 


\section{Data transfer and data management}

Since the commencement of the APLC cohort, de-identified data have been pooled twice into the centralised database. The first data pooling was carried out in August 2015 (baseline visits only) and the next data pooling was carried out in January 2017, which included baseline and all follow-up visits up to December 2016 (Table 2). During the time period between the two data transfers, most sites have recruited additional patients. New centres have recently joined the APLC and have yet to commence patient recruitment (Figure 1). The number of patients included in analyses in such studies is often less than the number of enrolled patients due to data cleaning stringency.

The pooled APLC cohort database is managed by investigators at Monash University on behalf of the APLC, in accordance with the operating principles and technical standards for Australian clinical quality registries published by the Australian Commission on Safety and Quality in Healthcare (31). The pooled database is stored in Monash University's secure file servers, which are backed up nightly, and access is limited to the APLC Data Manager.

\section{Data access and research release}

Access to APLC pooled data is subject to the specific access guidelines outlined in the APLC Data Access Policy (provided upon request). We welcome requests for aggregate (summary) data or to perform analyses of new research questions, and such requests can be submitted to the APLC steering committee via Data Manager.

\section{RESULTS}

To date, the APLC cohort comprises 2160 patients with >12,000 visits from 14 centres in 10 countries (Table 2). Baseline characteristics of these patients are summarised in Table 3. In brief, 93\% of the APLC cohort is female with a median age ([inter-quartile range (IQR)] (range)) of 40 years $([31,51](18,77))$. The majority of APLC patients are of Asian ethnicity, predominantly Chinese (49\%) followed by Thai $(16 \%)$. Approximately $8 \%$ were of Caucasian ethnicity. About $8 \%$ had a family history of lupus, and the majority (45\%) had a post-secondary education level. Approximately $78 \%$ of patients were on prednisolone, $69 \%$ were on antimalarials and $50 \%$ were on immunosuppressants at recruitment. About $45 \%$ were in LLDAS at recruitment (Table 3). 
Two papers have been published based on the baseline data pooled in 2015, in which we examined the frequency and predictors of LLDAS (32), and its association with HRQoL (33) using cross-sectional analyses (https://www.asiapacificlupus.com/publications). In brief, we observed that patients with shorter disease duration, a history of cutaneous and/or renal disease, elevated anti-dsDNA or hypocomplementaemia were less likely to be in LLDAS. When countries were compared, LLDAS was positively associated with higher national social wealth as measured by the Gross Domestic Product per capita, but not with any particular ethnic group(s) (32). We also found that patients who were in LLDAS at baseline had significantly better HRQoL measured in terms of Physical and Mental Component Summary scores (PCS and MCS, both with p-values less than 0.001) and in multiple individual SF-36 domain scores, when compared to those who were not in LLDAS (33).

The current patient cohort has a median length of follow up of two years. Patients from this cohort with multiple visits will be used to conduct the first ever prospective validation of LLDAS.

\section{DISCUSSION}

Within a short period, the APLC has established the largest cohort of SLE patients in the Asia Pacific region, and one of the largest contemporary cohorts of SLE patients under study worldwide. Several high-quality lupus cohorts exist, but they are predominantly in Western countries and include historical data going back up to 20 years. The Toronto Lupus Cohort in Canada, and the Hopkins lupus cohort in USA, are two of the longest running single centre cohorts, which have close to 2,000 patients each with a mixture of long-standing and new patients who are being followed up on annual basis (34) (35).. The LUMINA (Lupus in Minorities: Nature vs. Nurture) cohort and the Euro-lupus project are both large multisite multinational cohorts, however both lack significant representation of Asians (36) (37). The SLICC inception cohort has $>1700$ patients and includes almost $16 \%$ patients of Asian ethnicity, with longitudinal collection of data for patients recruited from 2000 to 2011 from 31 centres in 11 countries in North America, Latin America, Europe and Asia (38). However, this cohort has data collected at annual visits only (38), which does not capture the fluctuating natural history of SLE disease activity. The APLC cohort is the only large multicentre cohort with a significant proportion of Asian SLE patients, and which has frequently captured extensive data on disease activity, medication exposure and laboratory results, which makes it one of the most well described SLE cohorts in the world. 
Data collected in the course of the APLC LLDAS validation study will represent a unique resource for future research. In the long term, data from the APLC will be used to evaluate other endpoint definitions, such as the DORIS remission definitions (39). It is essential for remission definitions adopted to be clearly distinguished from LLDAS in both attainability and outcome (40). We intend to soon analyse the results of prospective evaluation of LLDAS and its association with damage accrual, as well as a rigorous evaluation of existing and proposed remission definitions in comparison to LLDAS. We also plan to study quality of care by identifying gaps in best practice and benchmarking performance, and to evaluate with considerable power associations of outcome with various clinical manifestations and treatment.

One of the drawbacks of the APLC is that it is still a young cohort with a relatively short follow up period. Since protection against organ damage accrual is the main outcome measure in the LLDAS validation study, it is preferable to have longer follow up. The APLC cohort is now in the process of extension (continuing data collection of existing patients) and expansion (recruiting new patients). Additionally, the accessibility of health care by SLE patients varies greatly across countries and this could also be a limitation of studies of the APLC cohort, but such is the case with any international cohort. The national wealth of each country has been used as a surrogate variable to account for broad differences in socioeconomic status. The APLC cohort also provides a platform to formally identify how outcomes differ among countries with different health systems. Comorbidities are not captured in the current data collection, but the APLC intends to incorporate this data capture in the near future using an online database for global data capture.

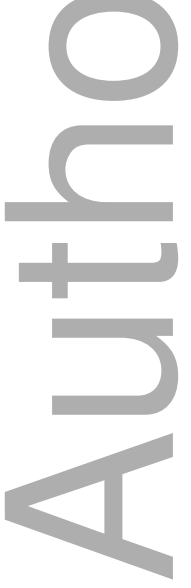




\section{ACKNOWLEDGEMENT}

We thank all the participants in the APLC for their participation and all the data collectors across the region for their ongoing support for the study. The initial funding for the generation of the APLC concept came from the host universities who employ the founders. GlaxoSmithKline provided the first direct funding to the APLC in support of establishing the cohort, and several other companies including AstraZeneca, Bristol-Myers Squibb, Janssen and UCB Biopharma SPRL have funded the APLC via unrestricted grants or specific project funding. These funding bodies have no role in study design and publication of study findings, and have no access to raw data. Funds are used to employ a data manager responsible for data collection and analysis, and some funds are shared among the institutions to support data collection.

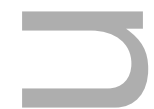

\section{CONFLICT OF INTEREST}

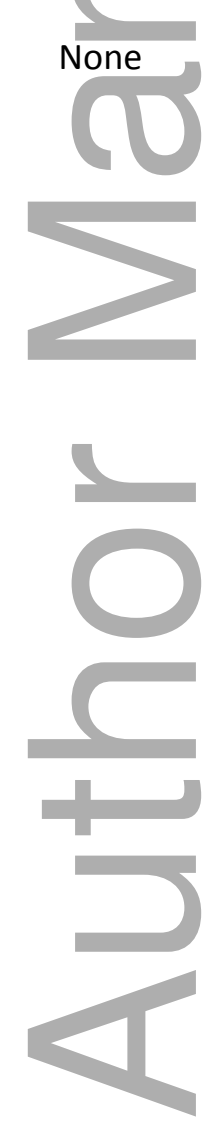




\section{REFERENCES}

1. Zharkova O, Celhar T, Cravens PD, Satterthwaite AB, Fairhurst AM, Davis LS. Pathways leading to an immunological disease: systemic lupus erythematosus. Rheumatology. 2017;56(suppl_1):i55-i66.

2. Jakes RW, Bae SC, Louthrenoo W, Mok CC, Navarra SV, Kwon N. Systematic review of the epidemiology of systemic lupus erythematosus in the Asia-Pacific region: prevalence, incidence, clinical features, and mortality. Arthritis care \& research. 2012;64(2):159-68.

3. Wolfe F, Michaud K, Li T, Katz RS. EQ-5D and SF-36 quality of life measures in systemic lupus erythematosus: comparisons with rheumatoid arthritis, noninflammatory rheumatic disorders, and fibromyalgia. The Journal of rheumatology. 2010;37(2):296-304.

4. Rivest C, Lew RA, Welsing PM, Sangha O, Wright EA, Roberts WN, et al. Association between clinical factors, socioeconomic status, and organ damage in recent onset systemic lupus erythematosus. The Journal of rheumatology. 2000;27(3):680-4.

5. Chatham WW, Kimberly RP. Treatment of lupus with corticosteroids. Lupus. 2001;10(3):140-7.

6. Chambers SA, Allen E, Rahman A, Isenberg D. Damage and mortality in a group of British patients with systemic lupus erythematosus followed up for over 10 years. Rheumatology. 2009;48(6):673-5.

7. Li PH, Lau CS. Lupus in the far east: a modern epidemic. International journal of rheumatic diseases. 2017;20(5):523-5.

8. Mok MY, Li WL. Do Asian patients have worse lupus? Lupus. 2010;19(12):1384-90.

9. Lau CS, Mak A. The socioeconomic burden of SLE. Nature reviews Rheumatology. 2009;5(7):400-4.

10. Urowitz MB, Gladman DD, Tom BD, Ibanez D, Farewell VT. Changing patterns in mortality and disease outcomes for patients with systemic lupus erythematosus. The Journal of rheumatology. 2008;35(11):2152-8.

11. Marion TN, Postlethwaite AE. Chance, genetics, and the heterogeneity of disease and pathogenesis in systemic lupus erythematosus. Seminars in immunopathology. 2014;36(5):495-517.

12. Franklyn K, Hoi A, Nikpour M, Morand EF. The need to define treatment goals for systemic lupus erythematosus. Nature reviews Rheumatology. 2014;10(9):567-71.

This article is protected by copyright. All rights reserved 
13. van Vollenhoven RF, Mosca M, Bertsias G, Isenberg D, Kuhn A, Lerstrom K, et al. Treatto-target in systemic lupus erythematosus: recommendations from an international task force. Annals of the rheumatic diseases. 2014;73(6):958-67.

14. Smolen JS, Breedveld FC, Burmester GR, Bykerk V, Dougados M, Emery P, et al. Treating rheumatoid arthritis to target: 2014 update of the recommendations of an international task force. Annals of the rheumatic diseases. 2016;75(1):3-15.

15. Urowitz MB, Feletar M, Bruce IN, Ibanez D, Gladman DD. Prolonged remission in systemic lupus erythematosus. The Journal of rheumatology. 2005;32(8):1467-72.

16. Nikpour M, Urowitz MB, Ibanez D, Gladman DD. Frequency and determinants of flare and persistently active disease in systemic lupus erythematosus. Arthritis and rheumatism. 2009;61(9):1152-8.

17. Curtis JR, Shan Y, Harrold L, Zhang J, Greenberg JD, Reed GW. Patient perspectives on achieving treat-to-target goals: a critical examination of patient-reported outcomes. Arthritis care \& research. 2013;65(10):1707-12.

18. Franklyn K, Lau CS, Navarra SV, Louthrenoo W, Lateef A, Hamijoyo L, et al. Definition and initial validation of a Lupus Low Disease Activity State (LLDAS). Annals of the rheumatic diseases. 2016;75(9):1615-21.

19. Tsang-A-Sjoe MWP, Bultink IEM, Heslinga M, Voskuyl AE. Both prolonged remission and Lupus Low Disease Activity State are associated with reduced damage accrual in systemic lupus erythematosus. Rheumatology. 2017;56(1):121-8.

20. Ordi-Ros J, Sáez-Comet L, Pérez-Conesa M, Vidal X, Mitjavila F, Castro Salomó A, et al. Enteric-coated mycophenolate sodium versus azathioprine in patients with active systemic lupus erythematosus: a randomised clinical trial. Ann Rheum Dis. 2017.

21. Morand EF, Trasieva T, Berglind A, Illei GG, Tummala R. Lupus Low Disease Activity State (LLDAS) attainment discriminates responders in a systemic lupus erythematosus trial: post-hocanalysis of the Phase Ilb MUSE trial of anifrolumab. Ann Rheum Dis. 2018:212504-9.

22. Zen M, laccarino L, Gatto M, Saccon F, Larosa M, Ghirardello A, et al. Lupus low disease activity state is associated with a decrease in damage progression in Caucasian patients with SLE, but overlaps with remission. Ann Rheum Dis. 2017;77(1):annrheumdis-2017-211613-110.

23. Piga M, Floris A, Cappellazzo G, Chessa E, Congia M, Mathieu A, et al. Failure to achieve lupus low disease activity state (LLDAS) six months after diagnosis is associated with early damage accrual in Caucasian patients with systemic lupus erythematosus. Arthritis research \&amp; therapy. 2017;19(1):247.

This article is protected by copyright. All rights reserved 
24. Hochberg MC. Updating the American College of Rheumatology revised criteria for the classification of systemic lupus erythematosus. Arthritis and rheumatism. 1997;40(9):1725.

25. Petri M, Orbai AM, Alarcon GS, Gordon C, Merrill JT, Fortin PR, et al. Derivation and validation of the Systemic Lupus International Collaborating Clinics classification criteria for systemic lupus erythematosus. Arthritis and rheumatism. 2012;64(8):2677-86.

26. Stoll T, Seifert B, Isenberg DA. SLICC/ACR Damage Index is valid, and renal and pulmonary organ scores are predictors of severe outcome in patients with systemic lupus erythematosus. Br J Rheumatol. 1996;35(3):248-54.

27. Ware JE, Jr., Sherbourne CD. The MOS 36-item short-form health survey (SF-36). I. Conceptual framework and item selection. Med Care. 1992;30(6):473-83.

28. Touma Z, Urowitz MB, Ibanez D, Gladman DD. SLEDAI-2K 10 days versus SLEDAI-2K 30 days in a longitudinal evaluation. Lupus. 2011;20(1):67-70.

29. Isenberg DA, Allen E, Farewell V, D'Cruz D, Alarcon GS, Aranow C, et al. An assessment of disease flare in patients with systemic lupus erythematosus: a comparison of BILAG 2004 and the flare version of SELENA. Annals of the rheumatic diseases. 2011;70(1):54-9.

30. Furie RA, Petri MA, Wallace DJ, Ginzler EM, Merrill JT, Stohl W, et al. Novel evidencebased systemic lupus erythematosus responder index. Arthritis and rheumatism. 2009;61(9):1143-51.

31. Care ACOSaQiH. Operating Principles and Technical Standards for Australian Clinical Quality Registries. 2008.

32. Golder V, Kandane-Rathnayake R, Hoi AY, Huq M, Louthrenoo W, An Y, et al. Frequency and predictors of the lupus low disease activity state in a multi-national and multiethnic cohort. Arthritis research \& therapy. 2016;18(1):260.

33. Golder V, Kandane-Rathnayake R, Hoi AY, Huq M, Louthrenoo W, An Y, et al. Association of the lupus low disease activity state (LLDAS) with health-related quality of life in a multinational prospective study. Arthritis research \& therapy. 2017;19(1):62.

34. Polachek A, Gladman DD, Su J, Urowitz MB. Defining Low Disease Activity in Systemic Lupus Erythematosus. Arthritis care \& research. 2017;69(7):997-1003.

35. Fangtham M, Petri M. 2013 update: Hopkins lupus cohort. Current rheumatology reports. 2013;15(9):360.

36. Alarcon GS. Multiethnic lupus cohorts: what have they taught us? Reumatologia clinica. 2011;7(1):3-6. 
37. Cervera R, Khamashta MA, Hughes GR. The Euro-lupus project: epidemiology of systemic lupus erythematosus in Europe. Lupus. 2009;18(10):869-74.

38. Bruce IN, O'Keeffe AG, Farewell V, Hanly JG, Manzi S, Su L, et al. Factors associated with damage accrual in patients with systemic lupus erythematosus: results from the Systemic Lupus International Collaborating Clinics (SLICC) Inception Cohort. Annals of the rheumatic diseases. 2015;74(9):1706-13.

39. van Vollenhoven R, Voskuyl A, Bertsias G, Aranow C, Aringer M, Arnaud L, et al. A framework for remission in SLE: consensus findings from a large international task force on definitions of remission in SLE (DORIS). Ann Rheum Dis. 2016.

40. Morand EF. Connective tissue diseases: Remission in SLE - are we there yet? Nature reviews Rheumatology. 2016;12(12):696-8.

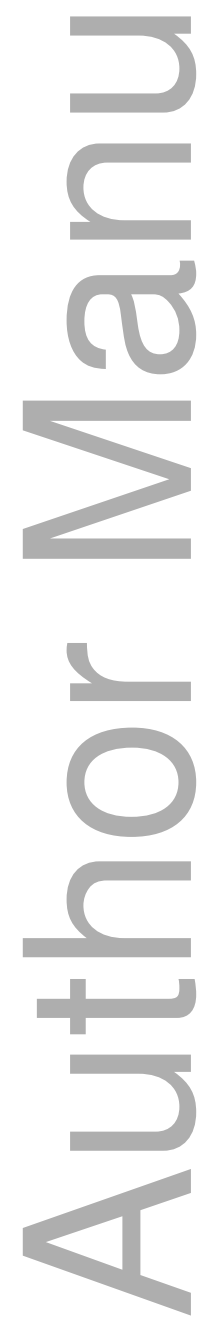


Table 1 - Data items collected in the APLC cohort

\begin{tabular}{|c|c|c|c|}
\hline Measures & $\begin{array}{c}\text { Baseline } \\
\text { (recruitment) }\end{array}$ & $\begin{array}{c}\text { Routine } \\
\text { Follow ups }\end{array}$ & Annual Visits \\
\hline $\begin{array}{l}\text { Visit date } \\
\text { Demographics }\end{array}$ & $\checkmark$ & $\checkmark$ & $\checkmark$ \\
\hline $\begin{array}{l}\text { Date of Birth } \\
\text { Gender } \\
\text { Ethnicity } \\
\text { Year of SLE onset } \\
\text { Year of Diagnosis } \\
\text { Smoking at recruitment } \\
\text { Family History of SLE } \\
\text { Educational Level }\end{array}$ & & & \\
\hline $\begin{array}{l}\frac{\text { Diagnosis Criteria }}{\text { ACR criteria }} \\
\text { SLICC Classification criteria }\end{array}$ & $\checkmark$ & & 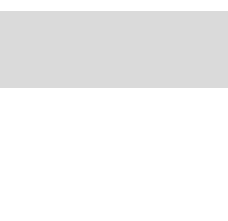 \\
\hline Pathology Data & $\checkmark$ & $\checkmark$ & $\checkmark$ \\
\hline $\begin{array}{l}\text { Creatinine } \\
\text { eGFR } \\
\text { Urine Protein/creatinine ratio } \\
\text { Haemoglobin } \\
\text { White Cell Count (WCC) } \\
\text { Platelet } \\
\text { Neutrophils } \\
\text { Lymphocytes }\end{array}$ & & & \\
\hline
\end{tabular}

This article is protected by copyright. All rights reserved 


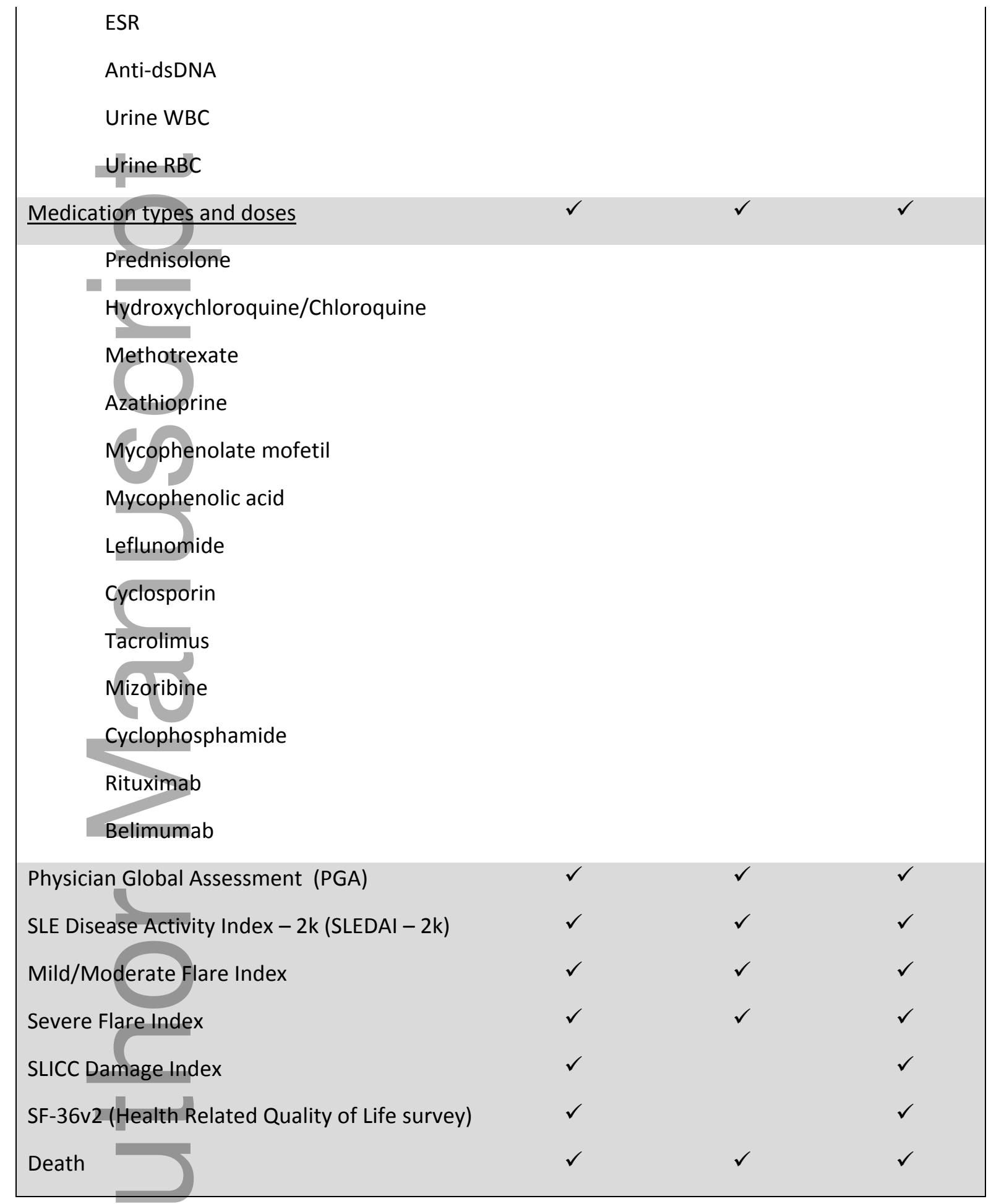

This article is protected by copyright. All rights reserved 
Table 2 - Number of patients and visits in 2015 and 2017 APLC cohort databases

\begin{tabular}{|c|c|c|c|}
\hline & 2015 Dataset & \multicolumn{2}{|c|}{2017 Dataset } \\
\hline & No. of patients & \multicolumn{2}{|c|}{ No. of } \\
\hline & \& visits & Patients & Visits \\
\hline Royal Adelaide H./Flinders Medical Centre, SA, Australia & 33 & 44 & 170 \\
\hline Monash H./Uni., VIC, Australia & 169 & 189 & 1,576 \\
\hline Liverpool H., NSW, Australia & 38 & 40 & 190 \\
\hline St. Vincent's H., VIC, Australia & 0 & 58 & 176 \\
\hline Peking Uni. Health Science Center, Beijing, China & 235 & 235 & $235^{+}$ \\
\hline The University of Hong Kong, Hong Kong & 190 & 190 & $190^{+}$ \\
\hline Padjadjaran Uni., Indonesia & 98 & 107 & 905 \\
\hline Tokyo Women's Medical Uni., Japan & 0 & 97 & 461 \\
\hline Uni. Malaya, Malaysia & 193 & 184 & 919 \\
\hline Uni. Santo Tomas H., Philippines & 124 & 124 & 571 \\
\hline National University H., Singapore & 179 & 201 & 1,570 \\
\hline Tan Tock Seng H., Singapore & 42 & 54 & 387 \\
\hline Chang-Gung Memorial Hospital, Taiwan & 295 & 300 & 2,373 \\
\hline Chiang Mai Uni., Thailand & 250 & 337 & 3,419 \\
\hline Total & 1846 & 2160 & 12762 \\
\hline
\end{tabular}

†Baseline visits only 
Table 3 - APLC participant characteristics reported at recruitment (2017 dataset)

\begin{tabular}{|c|c|}
\hline r & $\begin{array}{c}\text { Descriptive Statistics } \\
\text { Total }=\mathbf{2 1 6 0}\end{array}$ \\
\hline Demographics & n (\%) \\
\hline Age at enrolment (years), median [IQR](range) & $40[31,51](18,77)$ \\
\hline Age at diagnosis (years), median [IQR](range) & $29[21,39](1,74)$ \\
\hline Female & 2007 (93\%) \\
\hline Family history of $\mathrm{SLE}^{1}$ & $143(8 \%)$ \\
\hline Current smoker at baseline $^{2}$ & $91(5 \%)$ \\
\hline Australia & $331(15 \%)$ \\
\hline China & $235(11 \%)$ \\
\hline Hong Kong & $190(9 \%)$ \\
\hline Indonesia & $107(5 \%)$ \\
\hline Japan & $97(4 \%)$ \\
\hline Malaysia & $184(8 \%)$ \\
\hline Philippines & $124(6 \%)$ \\
\hline Singapore & $255(12 \%)$ \\
\hline Taiwan & $300(14 \%)$ \\
\hline Thailand & $337(16 \%)$ \\
\hline Caucasian & $178(8 \%)$ \\
\hline Chinese & $1051(49 \%)$ \\
\hline Filipino & $136(6 \%)$ \\
\hline Indonesian & $111(5 \%)$ \\
\hline Japanese & $97(4 \%)$ \\
\hline Malay & $101(5 \%)$ \\
\hline Other & $40(2 \%)$ \\
\hline South Asians & $70(3 \%)$ \\
\hline Thai & $345(16 \%)$ \\
\hline Vietnamese/Cambodian & $31(1 \%)$ \\
\hline
\end{tabular}

This article is protected by copyright. All rights reserved 


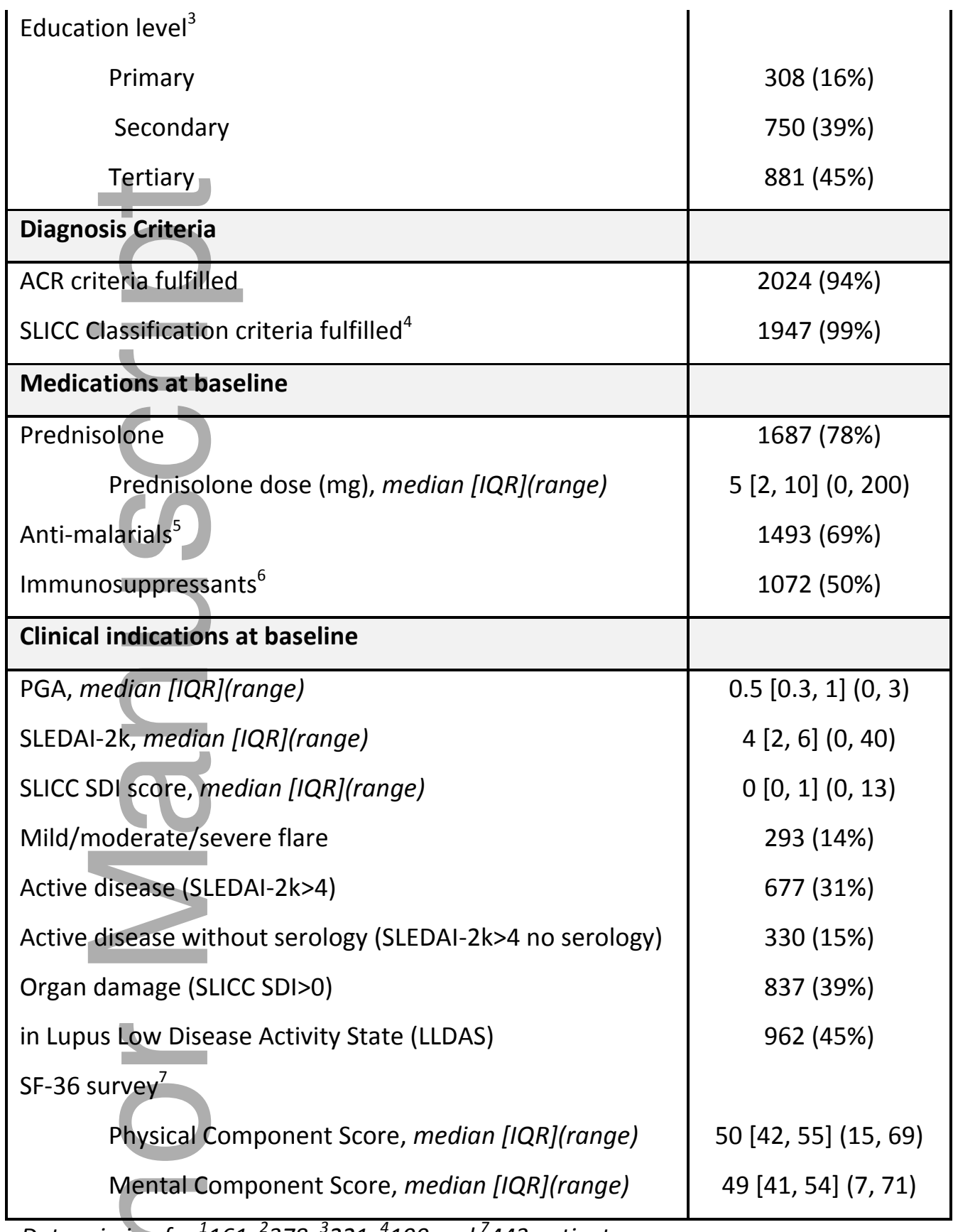

Data missing for ${ }^{1} 161,{ }^{2} 378,{ }^{3} 221,{ }^{4} 190$ and ${ }^{7} 443$ patients.

${ }^{5}$ Anti-malarials include hydroxychloroquine and chloroquine

${ }^{6}$ Immunosupressessants include methotrexate, azathioprine, mycophenolate, mycophenolic acid, leflunomide, cyclosporine, tacrolimus, mizoribine, rituximab \& belimumab $I Q R=$ inter-quartile range 


\section{Figure Legends}

Figure 1 - Asia Pacific Lupus Collaboration Sites; new sites are in italic

Figure 2 - Consensus Definition of Lupus Low Disease Activity State (LLDAS)

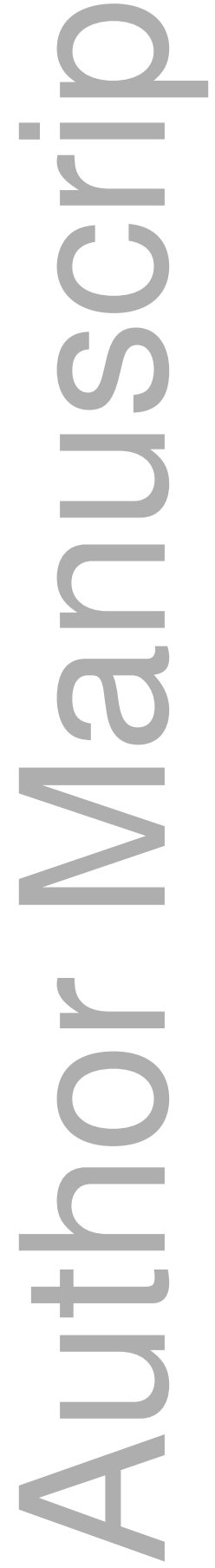

This article is protected by copyright. All rights reserved 


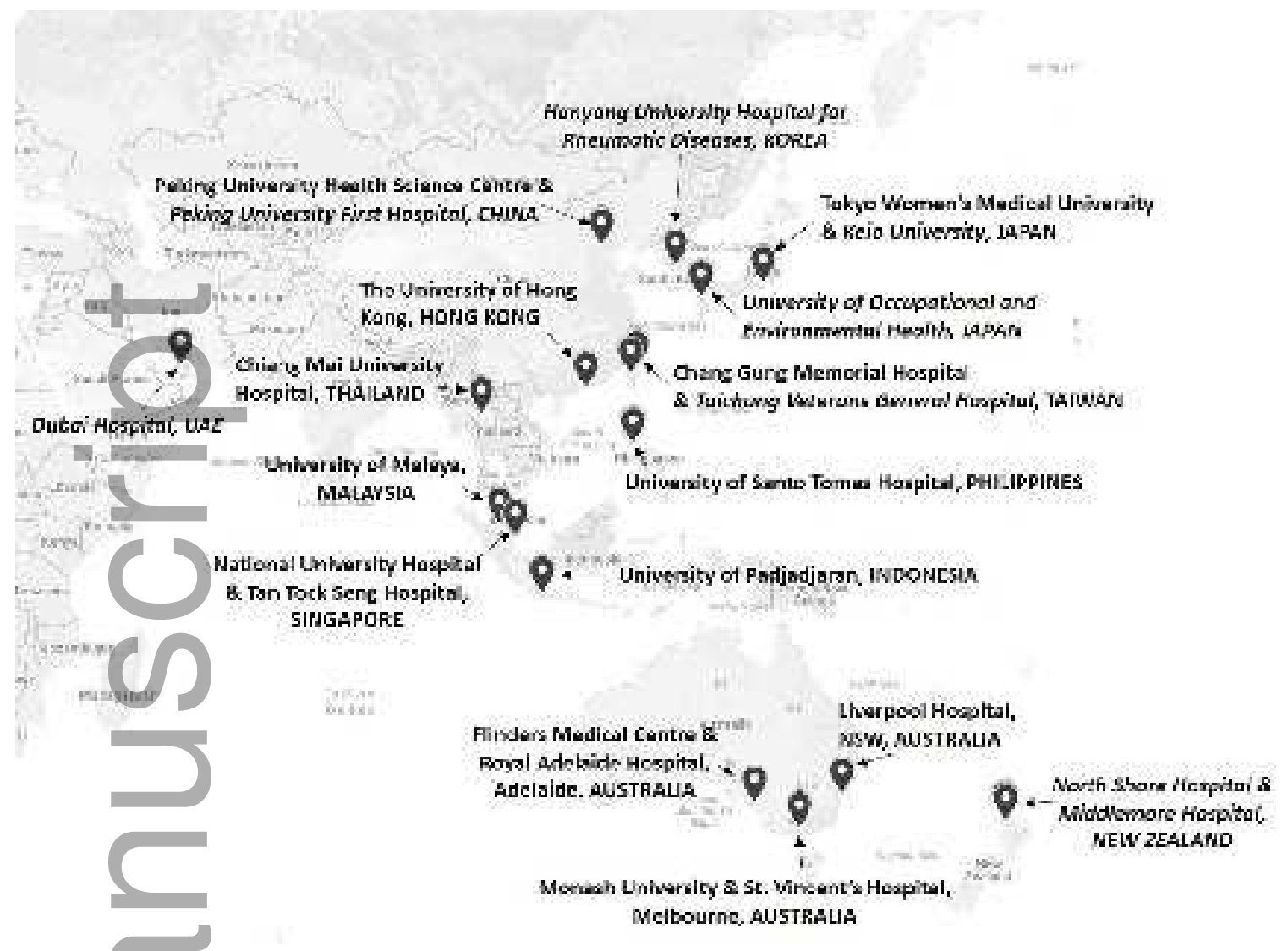

apl_13431_f1.jpg

This article is protected by copyright. All rights reserved 


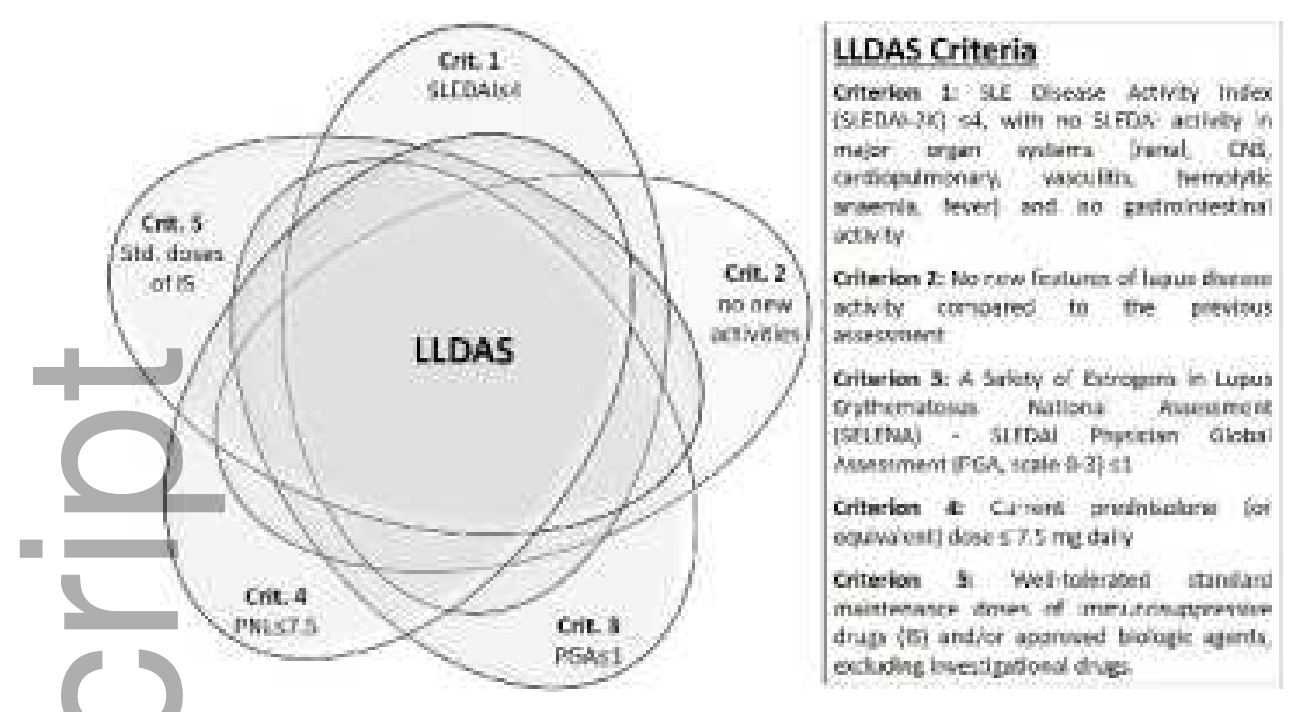

apl_13431_f2.jpg
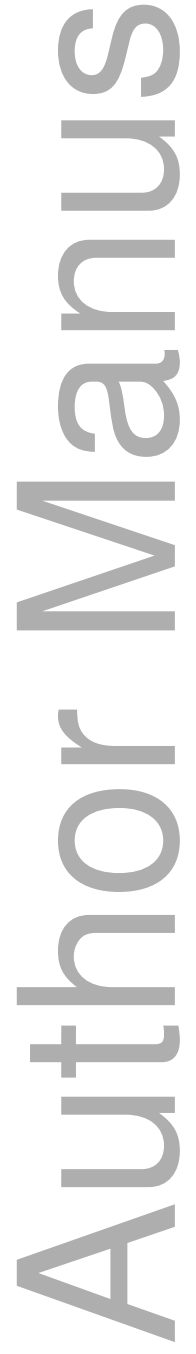


\section{University Library}

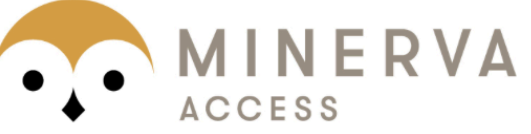

A gateway to Melbourne's research publications

Minerva Access is the Institutional Repository of The University of Melbourne

\section{Author/s:}

Kandane-Rathnayake, R;Golder, V;Louthrenoo, W;Luo, S-F;Wu, Y-JJ;Li, Z;An, Y;Lateef, A;Sockalingam, S;Navarra, SV;Zamora, L;Hamijoyo, L;Katsumata, Y;Harigai, M;Chan, M;O'Neill, S;Goldblatt, F;Hao, Y;Zhang, Z;Al-Saleh, J;Khamashta, M;Takeuchi, T;Tanaka, Y;Bae, S-C;Lau, CS;Hoi, A;Nikpour, M;Morand, EF

Title:

Development of the Asia Pacific Lupus Collaboration cohort

Date:

2019-03-01

\section{Citation:}

Kandane-Rathnayake, R., Golder, V., Louthrenoo, W., Luo, S. -F., Wu, Y. -J. J., Li, Z., An, Y., Lateef, A., Sockalingam, S., Navarra, S. V., Zamora, L., Hamijoyo, L., Katsumata, Y., Harigai, M., Chan, M., O'Neill, S., Goldblatt, F., Hao, Y., Zhang, Z. ,... Morand, E. F. (2019). Development of the Asia Pacific Lupus Collaboration cohort. INTERNATIONAL JOURNAL OF RHEUMATIC DISEASES, 22 (3), pp.425-433. https://doi.org/10.1111/1756-185X.13431.

Persistent Link:

http://hdl.handle.net/11343/284735 